\title{
Patients Using an Online Forum for Reporting Progress When Engaging With a Six-Week Exercise Program for Knee Conditioning: Feasibility Study
}

Philip Bright ${ }^{1,2 *}$, BSc (Hons), PGCRM, PGCHE, PhD; Karen Hambly ${ }^{3 *}$, BSc (Physiotherapy), PhD

\footnotetext{
${ }^{1}$ School of Sport and Exercise Sciences, Medway Campus, University of Kent, Chatham, United Kingdom

${ }^{2}$ Research Department, European School of Osteopathy, Maidstone, United Kingdom

${ }^{3}$ School of Sport and Exercise Sciences, Medway Campus, University of Kent, Maidstone, United Kingdom

*all authors contributed equally
}

Corresponding Author:

Philip Bright, BSc (Hons), PGCRM, PGCHE, PhD

Research Department

European School of Osteopathy

Boxley House

The Street, Boxley

Maidstone, ME14 3DZ

United Kingdom

Phone: 4401622671558

Email: philbright@eso.ac.uk

\section{Abstract}

Background: The use of electronic health (eHealth) and Web-based resources for patients with knee pain is expanding. Padlet is an online noticeboard that can facilitate patient interaction by posting virtual "sticky notes."

Objective: The primary aim of this study was to determine feasibility of patients in a 6-week knee exercise program using Padlet as an online forum for self-reporting on outcome progression.

Methods: Undergraduate manual therapy students were recruited as part of a 6-week study into knee conditioning. Participants were encouraged to post maximum effort readings from quadriceps and gluteal home exercises captured from standard bathroom scales on a bespoke Padlet. Experience and progression reporting were encouraged. Posted data were analyzed for association between engagement, entry frequency, and participant characteristics. Individual data facilitated single-subject, multiple-baseline analysis using statistical process control. Experiential narrative was analyzed thematically.

Results: Nineteen participants were recruited (47\%, 9/19 female); ages ranged from 19 to 53 years. Twelve individuals (63\%) opted to engage with the forum (range 4-40 entries), with five (42\%) reporting across all 6 weeks. Gender did not influence reporting (odds ratio [OR] 0.76, 95\% CI 0.06-6.93). No significant difference manifested between body mass index and engagement $P=.46)$; age and entry frequency did not correlate $\left(\mathrm{R}^{2}=.054,95 \% \mathrm{CI}-0.42\right.$ to $\left.0.51, P=.83\right)$. Statistically significant conditioning profiles arose in single participants. Themes of pain, mitigation, and response were inducted from the experiences posted.

Conclusions: Patients will engage with an online forum for reporting progress when undertaking exercise programs. In contrast to related literature, no significant association was found with reporting and gender, age, or body mass index. Individual posted data allowed multiple-baseline analysis and experiential induction from participants. Conditioning responses were evident on visual inspection. The importance of individualized visual data to patients and the role of forums in monitoring patients' progress in symptomatic knee pain populations need further consideration.

(JMIR Rehabil Assist Technol 2018;5(1):e9) doi: 10.2196/rehab.8567

\section{KEYWORDS}

eHealth; social media; exercise therapy; rehabilitation 


\section{Introduction}

The use of Web-based resources and eHealth apps for patients with knee pain is an area of expansion [1,2]. The term eHealth encompasses technology delivered through computer, hand-held tablet, or mobile phone that supports patients and practitioners in decision making, coping strategies, treatment approaches, or functional improvement [3]. There are a range of knee conditions such as osteoarthritis, arthroplasty, and cruciate ligament tears that are being informed by patient decision aids, electronic patient-reported outcomes, and biofeedback software [4-6]. Positive effects are noted across a range of conditions including knee osteoarthritis, but further work is required on determining suitable interactions between patients and these eHealth measures $[7,8]$.

The cost of developing and delivering eHealth resources is considered to be offset by the ease of patient accessibility [9]. The lack of quality studies and the heterogeneous nature of conditions supported by eHealth prevent full unequivocal endorsement of the cost-effectiveness of technology-driven approaches [10,11]. The expedient delivery and low-cost development afforded by Web 2.0 apps may facilitate further access to eHealth [12] and wider health information technology [13], including patient-reported health records [14]. The Web 2.0 platform has increased participation through social media and the sharing of experience due to the ease of posting materials such as video files and online forums [15]. This latest generation of Internet development is seen as providing a collaborative medium for knowledge generation and dissemination [16]. This aligns to the potential interactive nature of eHealth programs that has been reported to facilitate health care engagement [17].

Educational research and pedagogic practice have been fruitful areas of exploration around Web 2.0 apps [18]. The option to motivate learners in ever more expansive ways of engagement adds to the wider participation aspirations of higher education [19]. There are a range of tools that allow for students to engage in learning and feedback in the Web 2.0 toolset that may have applicability in eHealth [18,20,21]. These tools have been deployed to support chronic conditions in older adults with regards to education and self-management; the pedagogue/student relationship transformed to clinician/patient with the shared aim of empowerment [22]. The exposure to the range of eHealth has been seen to bridge gender and age differences, but there is a suggestion that gender influences engagement with Web 2.0 apps [23]. Online social interaction has also been explored with respect to weight management facilitated through discussion boards; attrition rates are reportedly high in this area and little change is noted in body mass index (BMI) as a common outcome measure [24]. High $\mathrm{BMI}$ has been seen to be associated with higher attrition rates.

Padlet is a Web 2.0 online noticeboard that can be used to facilitate participant interaction by posting of multimedia files as virtual "sticky notes" with mediation by an administrator [25]. The scope for using this resource as an eHealth app has been investigated with some success in terms of engaging surgeons or clinicians to discuss cases in a forum setting [12]. The initial disadvantages described around mobile access have been addressed with the latest software release [26]. There is potential that this platform could facilitate an online health community; online health communities can be used to share patient and clinical experiences while disseminating expert-moderated knowledge [27]. These communities have the potential to allow patients to report progress and responses that are normally qualitative in nature [28]. With the range of biofeedback devices now available, the sharing of quantitative data to monitor patient progress and motivation via Web 2.0 apps has potential to influence compliance [29]. The use of the Padlet Web 2.0 platform to facilitate a patient-led, clinician-moderated online forum around knee conditioning exercises with biofeedback data has not been explored. The potential to use this type of forum for participant-specific primary data gathering is also an area requiring further investigation.

The aim of this study was to determine the feasibility of patients engaging with an online forum to report progress using biofeedback as part of a 6-week exercise program to improve knee function.

The primary objective was to facilitate a moderated, online community and explore participant characteristics that reportedly influence engagement, with a view to answer the following research question: is there a difference in reporting progress in an online forum based on gender, age, and BMI. A secondary objective was to ascertain if sufficient individual data were reported to complete a multiple-baseline case study for participants in the study. A tertiary objective was to establish if sufficient qualitative data were posted to allow induction of descriptive themes.

\section{Methods}

\section{Design}

This was a mixed-methods, quasi-experimental feasibility study with an integrated single-case, multiple-baseline, ABCD analysis and descriptive thematic summary.

\section{Participants}

As part of a parallel study into the effects of biofeedback on knee function, participants were recruited from current year 1 to 4 undergraduate students in the osteopathy program at the European School of Osteopathy and year 2 undergraduates in the sports therapy program at the University of Kent. Recruitment took place from August 2016 to January 2017, and student participants were invited to take part in the study via email and notices placed around campus. The inclusion criteria were male and female adult students who had daily access to bathroom scales, permitted receipt of reminders via text message, and had online access via any suitable device. The exclusion criteria were if they were suffering with bilateral knee or hip pain, undertook recurrent high-intensity physical training, or had an underlying metabolic disorder or neuromuscular condition.

\section{Online Forum Development}

The Padlet Web 2.0 app (Padlet Co, Sunnyvale, CA, USA) was used to develop the forum for posting of participant data; the 
Padlet platform facilitates multiple users sharing information and resources in a discrete environment. From the main site page, accessed via a personalized user and password, the "+make a Padlet" option was selected and a freeform option for the forum was selected as demonstrated in Figure 1.

As users were encouraged to share information and experiences. The posts were not anonymized, but oversight of the activity was conducted by the lead researchers on the study $(\mathrm{PB}, \mathrm{KH})$. A code of conduct was posted on the webpage to ensure acceptable standards of behavior were adopted. The details of this can be viewed in Textbox 1. Padlet also operates its own policy for reporting and removing inappropriate content in addition to user-defined practice available on their website.

\section{Procedure}

The following characteristic data were collected at baseline: height $(\mathrm{cm})$, weight $(\mathrm{kg})$, waist circumference $(\mathrm{cm})$, BMI $\left(\mathrm{kg} / \mathrm{m}^{2}\right)$, activity levels (11-point numerical rating scale), age, and gender. Participants were inducted into a knee program consisting of staged repetitions of a seated clamshell exercise (an adaptation from Distefano et al [30]) and a short arc quadriceps extension (Figure 2). The clamshell required participants to abduct the hip, contracting gluteals as hard as possible against the resistance of bathroom scales supported against a wall. The short arc quadriceps exercise required the participant to begin with a flexed knee over a foam roller (or equivalent bolster support) resting on bathroom scales positioned on a stable surface. The exercise was completed by contracting the quadriceps to extend the leg through the shortened range, registering contraction force on the scales beneath the roller. Both required a 5-second contraction and 2 -second relaxation phase.

Both exercises were repeated in sets of 12 and on both legs with a 60 -second relaxation phase between sets. The progression phases are depicted in Table 1.

Participants were sent text reminders on the days they were required to perform the exercises. The text messages included a hyperlink to the bespoke Padlet forum with instructions detailing their exercise and video guidance materials (see Multimedia Appendix 1). Participants were also requested to post readings of their maximum effort in kilograms, obtained from the bathroom scales, onto the online forum after each exercise session.

Figure 1. Creation page for Padlet wallpaper is indicative of background themes that can be customized. padlet

\section{(2) My radiant padlet} Made with joy

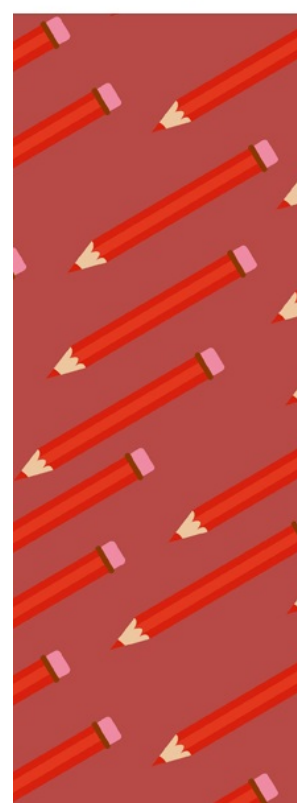

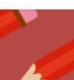

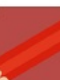

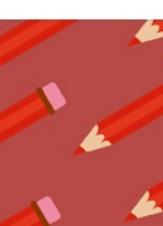
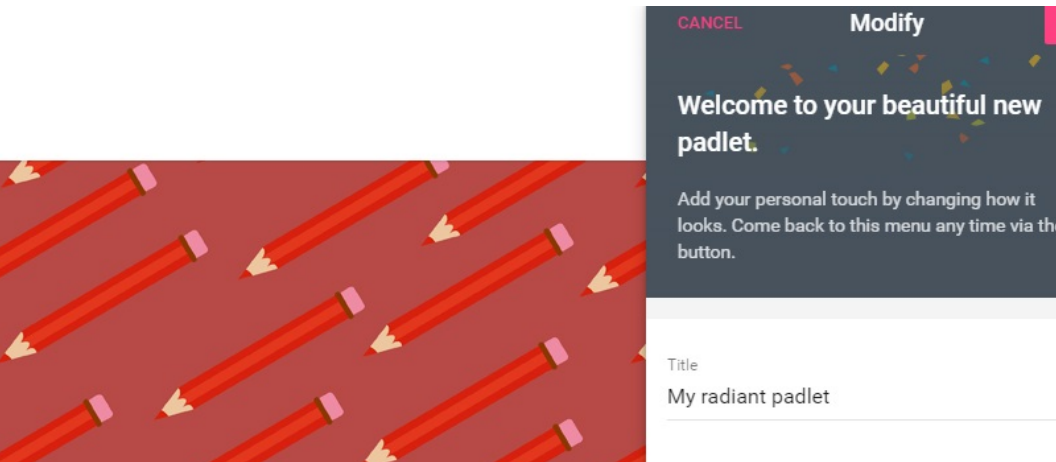
padlet.

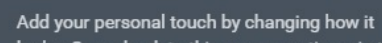
looks. Come back to this menu any time via the button.

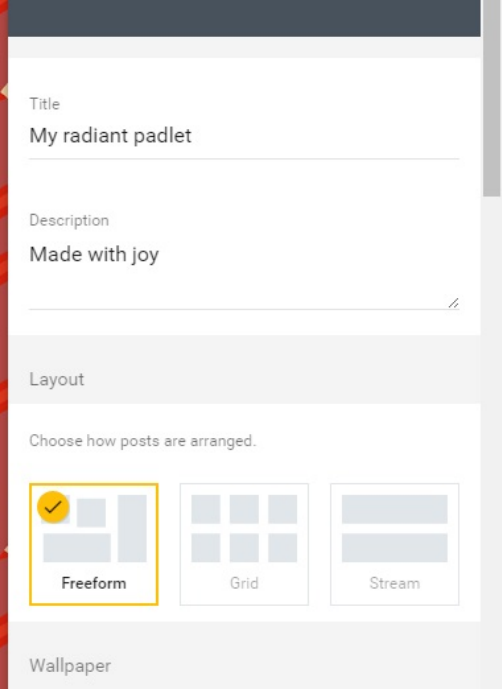

Textbox 1. Code of conduct displayed on Padlet. 
Figure 2. Seated clamshell and short-arc quadriceps exercise.

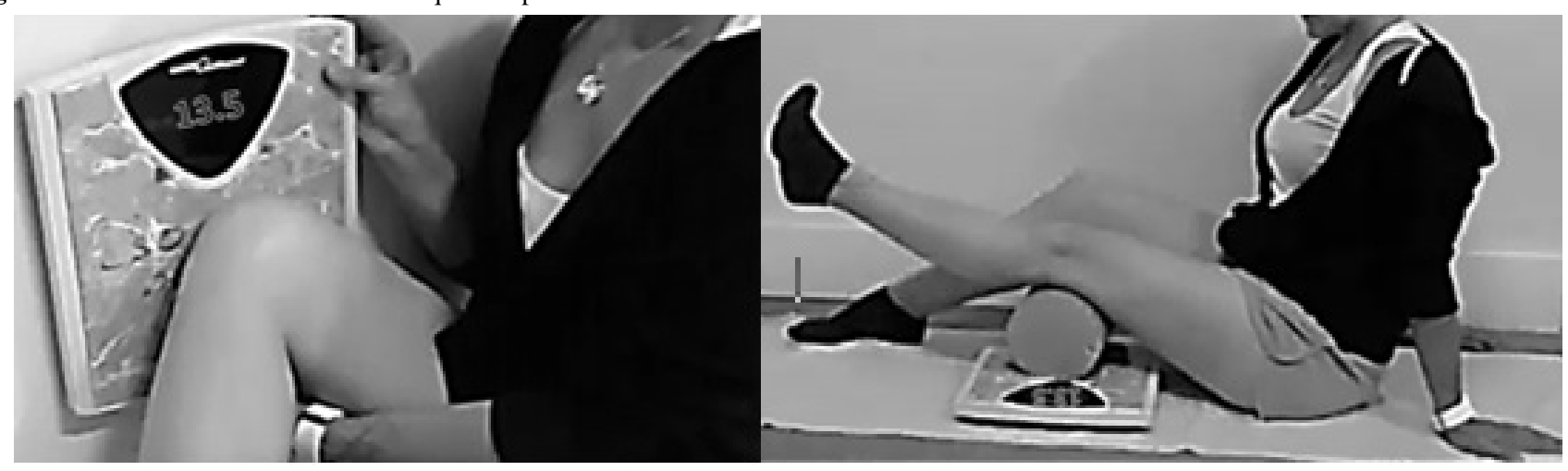

Table 1. Exercise progression details for participants.

\begin{tabular}{lll}
\hline Week & Exercise progression & Phase \\
\hline Weeks 1 and 2 & Maintain 2 sets of 12 repetitions every other day & Phase A \\
Weeks 3 and 4 & Maintain 3 sets of 12 repetitions every other day & Phase B \\
Week 5 & Maintain 4 sets of 12 repetitions every other day & Phase C \\
Week 6 & Maintain 5 sets of 12 repetitions every other day & Phase D \\
\hline
\end{tabular}

\section{Outcome Measures}

The primary outcome measure was the number of recorded entries detailing progression with the exercise schedule. A secondary outcome measure was the maximum voluntary contraction reading as captured from the bathroom scales from each exercise session. This was provided by the participants over all stages of engagement within the study.

\section{Ethics}

The study protocol was submitted to and approved by the Research Ethics Committees of the European School of Osteopathy and the School of Sport and Exercise Sciences, University of Kent, as part of a larger study exploring the use of biofeedback in a knee conditioning program.

\section{Statistical Analysis}

The Padlet postings were exported to a spreadsheet and aligned to participant baseline data. Summary and inferential statistics were calculated using Excel version 16 (Microsoft Corporation, Redmond, WA, USA) and Analyse-it version 4.65.3 (Analyse-it Software, Ltd, Leeds, UK). The numbers of recorded entries and BMI were assessed for distribution and equality of variance; gender group relationships and differences in reporting were explored using odds ratios with $95 \%$ confidence intervals and the Mann-Whitney $U$ test. Physical characteristics (BMI) and reporting differences were also explored using the Student $t$ test. Correlation between age and recording of entries was explored using the Spearman test; statistical significance was set at $P<.05$. Entries entered against one date were considered a single entry so multiple data added under a single date were only counted once. Discrete nominal values were derived from this in terms of binary (yes/no) indication of engagement with the forum to allow proportional analysis of association.

The staged recordings of maximum voluntary isometric contractions were extracted from the forum-recorded entries and three consistent datasets were analyzed using a multiple-baseline [31], ABCD case study [32] approach aligned to four (one baseline and three progressive) stages of exercise. A statistical process control (SPC) visual analysis [33] was applied to the resultant line graphs with means and standard deviations calculated from phase A baseline data. Statistical significance was regarded as two consecutive data points outside \pm 2 standard deviations in phases B, C, or D. Linear trend lines were added to indicate direction of individual progress. Finally, open-forum comments were analyzed within a descriptive thematic framework [34] and summarized in relation to the source participants.

\section{Results}

\section{Baseline Characteristics}

A total of 19 participants were recruited. The group was $47 \%$ female (9/19); age ranged from 19 to 53 years (mean 32.79, SD 10.78 years) and BMI ranged between 16.63 and $33.83 \mathrm{~kg} / \mathrm{m}^{2}$ (mean 25.02, SD $4.39 \mathrm{~kg} / \mathrm{m}^{2}$ ); eight individuals (42\%) were over the desired $25 \mathrm{~kg} / \mathrm{m}^{2}$. Mean height was 173.47 (SD 10.06) $\mathrm{cm}$, mean weight was 75.65 (SD 16.20) $\mathrm{kg}$, and median waist circumference was 84.0 (IQR 12.7) cm. Participant's mean activity rating was 4.42 (SD 1.30) and the median number of Padlet entries was 8 (IQR 16).

\section{Primary Outcome Measure}

Twelve individuals (63\%) opted to engage with the Padlet forum with entry frequency ranging from 4 to 40 . Follow-up on the seven who did not report outcomes elicited four replies; time constraints ( $n=3)$ and technophobia $(n=1)$ were cited as reasons for nonresponse. All individuals that initially reported outcomes went on to complete the exercise program regardless of dropout from the forum. The depiction of the finalized notice board entries can be viewed in Figure 3. 
Figure 3. Bespoke Padlet forum with participant and moderator posts. 
Inferential analysis of the influences on reporting by gender and age showed no statistical significance. The odds for male and female responders demonstrated that gender was not a factor in this sample for engaging with the forum activity (OR 0.76, 95\% CI 0.06-6.93). There was no significant difference between genders and entry frequency $(P=.97)$ or BMI and engagement $(P=.46)$. Age and entry frequency also showed no significant correlation $\left(R^{2}=.054,95 \% \mathrm{CI}-0.42\right.$ to $\left.0.51, P=.83\right)$.

\section{Secondary Outcome Measure}

Consistent data were reported across all 6 weeks of the study by five of the 12 participants who engaged with the forum $(58 \%$ attrition rate); three were selected for SPC analysis due to their staggered recruitment dates. The multiple-baseline analysis demonstrated the training effects of participants undertaking the staged exercises and the duration of their engagement with the short arc extension quadriceps exercise.

A progressive conditioning response is demonstrated in Figure 4 with the three line graphs; significant events are depicted in two of three SPC analyses. The first (SPC1) incurs two consecutive data points outside the upper 2 standard deviation threshold at the end of phase D; SPC3 demonstrates a range of significant improvements in reported muscle strength during phase B and D of the study.

\section{Qualitative Data}

Six participants $(50 \%, 6 / 12)$ provided limited commentary during their engagement with the online forum; examples are presented in Table 2 that demonstrate themes of pain, mitigation, and response. These participants were representative of the gender (40\% female) and age (mean 31, SD 10) of this study's demographics.

The individuals provided reflection on their experiences and progress in response to the exercises (female, age 22). The mitigating effects of pain were commonly reported in response to perceived decline in performance and reporting (male, age 29). A stoic sense of perseverance was interpreted from the commentary with an adaptation of technical approach when required (female, age 21; male, age 41).

Figure 4. Multiple-baseline analyses of single participant data with statistical thresholds and linear trend lines. SPC: statistical process control.

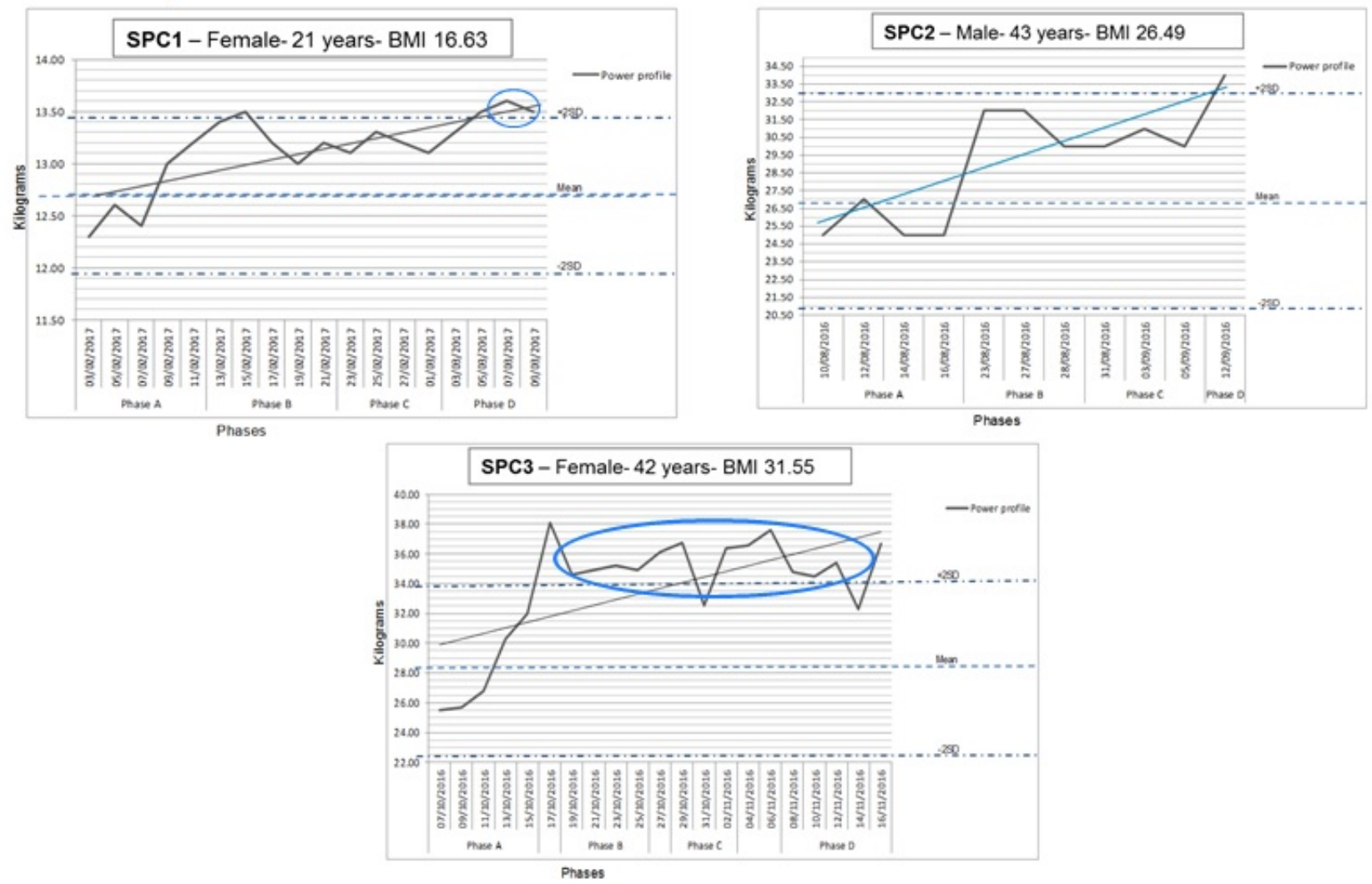


Table 2. Illustrative quotes from online forum.

\begin{tabular}{lll}
\hline Participant & Theme & Quote \\
\hline Female, age 22 & Mitigation & "Been getting more hypermobile in the last few days, which shows in the results" \\
Male, age 41 & Response & "Feedback is good, I push harder" \\
& $\begin{array}{l}\text { Mitigation/pain } \\
\text { Mitigation }\end{array}$ & "I changed how I was bracing myself and used a cushion on the scales for the glute exercise so it hurts less" \\
Female, age 21 & Mitigation & "A bit weaker over the last couple of days because of flu" \\
Male, age 42 & Pain & "I had an injury while climbing...it's painful" \\
Male, age 29 &
\end{tabular}

\section{Discussion}

The primary aim of this study was to determine the feasibility of patients using an online forum for reporting progress when engaging with a 6-week exercise program for managing knee pain. No statistically significant difference was found in reporting progress based on gender, age, or BMI. It was possible to use individuals' posted progress data to complete a multiple-baseline case study for a selection of participants in the study. Participants were willing to engage in limited discussion posts during their progression on the program.

Posting to the forum was initially at a moderate level and attrition rates were comparable with other studies exploring engagement with online discussion boards. The 58\% reported in this study is in the range of the 12 studies exceeding the $20 \%$ attrition rate in the review of Williams et al [24]. Within the scope of behavioral change in eHealth, the range of $41 \%$ to $84 \%$ attrition is reported in large randomized controlled trials [35]. The consistency of participants' reports within this study, facilitating individualized progression data, may be indicative of the stable core user remnant that prevails after initial early dropouts [36]. Further exploration of the benefits of self-reporting with the incentive of producing individual activity profiles is warranted, particularly within the scope of affordable technology and activity tracking [37].

Exercise adherence has been identified as a major contributor to exercise efficacy [38]. Participants that made initial engagement with recording their outcomes online committed to the 6-week program irrespective of report attrition. The access to the video instructions through the forum may have influenced this behavior because these media have been seen to improve exercise adherence $[39,40]$. The growth in interactive video technology may facilitate this further; real-time remote motion capture of patients, tracking, and analyzing movement, with feedback relayed direct from a therapist may be the panacea in this field [41]. There are implications for these types of systems in terms of sensitivity of personal data [42] and developing suitably secure software architecture is an ongoing challenge within the Web 2.0 milieu [43,44]. The integration of body sensor network information into this cloud computing platform and the volume of wearable devices (eg, FitBit, MOOV, Nike+) that can contribute to these biofeedback networks elicits a complex array of data [45]. This potentially lacks meaning or context for patients; the findings of this study demonstrate a simple solution to this complexity.
Age and social media engagement have been reported as conflicting characteristics in studies engaging eHealth with usage mediated by generation. Although engagement activity profiles may differ, those older than 65 years are comparable to those younger than 30 years in terms of the proportions reporting the use of the Internet for health-related information (53\% and 56\%, respectively) [46]. The age range in this study crossed Generations X and Y, but lacked engagement with senior citizens. Those older than 65 years are motivated to engage with eHealth and increased Internet use as a vital connection with the wider world, offsetting age-related functional changes [47] and physical inactivity [48]. Age was not seen as predictive of engagement in this study, but there is a suggestion that socioeconomic status is an overt influence on Internet use in relation to subjective health [49]. The sample in this study were drawn from undergraduate cohorts but the age span of 19 to 53 years indicates funding sources and social status could not be directly inferred and was not sought at the time of participation.

Gender and BMI may indicate a barrier to information technology use in adolescents and practitioners [50-52], but reported disparities in adoption of Internet-based health correspond more with lower income, educational attainment, ethnic background, and those for whom English is not their native language [53]. Gender and BMI influence on engagement was equivocal in terms of the odds reported in this study; the student sample here may be more consumer-driven, aligned to recent shifts in UK higher education with strong emphasis on student choice and experience and less on gender-based decisions [49]. The shifting engagement in this study's student participants may be tempered by self-determination and personal preference. Electronic media use has been reported as a risk factor for higher BMI, particularly within the adolescent female population [54]. Conversely, targeted eHealth solutions for weight management in young women suffer from poor uptake and user satisfaction ratings [55]. Activity and diet modification via specialized apps may offer an improved engagement profile around personal weight management in adults [56,57]. Similarly, perceived pressures reported by other health care undergraduates [58] may be applicable to this study and mitigated engagement. Time availability and pressures of course deadlines are also reported as inhibitors to activity-related eHealth [59]. The potential addictive impact of technology and reduced academic performance reported in other studies [60] may have been seen as prohibitive in this study's sample. Exploration of technology reliance and side effects on prolonged eHealth use is a conflicting relationship that warrants further exploration. 
The provision of individualized single-case data fed back to patients contributes to the ideal of personalized, preventive health care planning [61]. The ability for patients to report on their own progress with clinical home-based outcomes has been reported as vital to integrated electronic medical records [62]. The biofeedback information in this study could provide further complementary data to wearable devices $[45,63]$; this potentially negotiates the pathway between consumer mass adoption and practitioner caution in this developing area [64]. This study demonstrates that patients can have direct access to personal analytics and potentially aid in the management of ongoing conditions. The growing demand to use single-case analyses to inform effect size and meta-evidence [65-67] demands that "big data" from individual patients be used more constructively, particularly the patient-accessible visual analytics afforded within these designs [68].

This study's sample reported experiences around pain, mitigation, and responsiveness and this was within a recruitment strategy of asymptomatic participants. Subjective and objective pain measures have been widely explored in knee condition sufferers [69,70]. Qualitative data intimates that patients' outcomes and pain management should be considered on an individual basis [71] with online forums providing the validation, support, and resources as required [28]. The sample in this study described mitigating effects of pain in relation to the exercise task orientation. This contrasts with young symptomatic individuals that report the burden of musculoskeletal pain on quality of life and future prospects; the need for digital technologies to provide accessible, evidence-based resources is seen as vital in connecting these people with support from peers and health professionals [72]. The individuals in this study were potentially engaging from a sense of duty and felt compelled to offer mitigation when compliance wavered. There is suggestion that compelling pain management programs may only arise with a population that perceives the need for individualized care, particularly if that population feels disenfranchised [73].
Limitations of this study include selection bias with a convenience sample of undergraduate students. Only those prepared to commit to the program were included indicating that participants had an underlying motivation toward exercise. All participants were asymptomatic implicating the diversity in compliance; attrition could be further mitigated with a motivated symptomatic patient population. The extension to engage with people older than 65 years in future studies would allow the development of this type of online health community in condition-specific scenarios. Socioeconomic status was not captured by this study and this is seen as a key influence on access and engagement in the field of eHealth; such barriers to engagement have to be explored further. This study was able to demonstrate that a low-cost solution to developing an online health community is feasible and that individualized, patient-centric data can be produced from reporting biofeedback data on an online forum. Future research should look to investigate discordance between attitudes to technology-assisted health care, the importance of individualized visual data to patients, and the role of forums in monitoring patient engagement and progress in symptomatic populations.

Patients can engage with an online forum for reporting progress when complying with exercise programs for managing knee pain. No significant influence was found on reporting progress in an online forum based on gender, age, or BMI. It was possible to use individual posted progress data to complete a multiple-baseline case study for a selection of participants in the study. Participants were willing to engage in limited discussion posts during their progression on the program. The parochial nature of the sample is a limitation; future work in the area should look to address discordance between attitudes to technology-assisted health care, the importance of individualized visual data to patients, and the role of forums in monitoring patient engagement and progress in symptomatic knee pain populations. Socioeconomic background and other barriers to accessing these community forums need to be considered in this exploration.

\section{Acknowledgments}

The authors would like to thank Hannah Epps and Lee Thompson for their assistance in the recruitment of participants for this study.

\section{Conflicts of Interest}

None declared.

\section{Multimedia Appendix 1}

Powerpoint presentation of study.

\section{[PPTX File, 5MB-Multimedia Appendix 1]}

\section{References}

1. Pearson J, Walsh N, Carter D, Koskela S, Hurley M. Developing a web-based version of an exercise-based rehabilitation program for people with chronic knee and hip pain: a mixed methods study. JMIR Res Protoc 2016 May 19;5(2):e67 [FREE Full text] [doi: 10.2196/resprot.5446] [Medline: 27197702]

2. Hussain MS, Li J, Brindal E, van Kasteren Y, Varnfield M, Reeson A, et al. Supporting the delivery of total knee replacements care for both patients and their clinicians with a mobile app and web-based tool: randomized controlled trial protocol. JMIR Res Protoc 2017 Mar 01;6(3):e32 [FREE Full text] [doi: 10.2196/resprot.6498] [Medline: 28249832] 
3. Eysenbach G. What is e-health? J Med Internet Res 2001;3(2):E20 [FREE Full text] [doi: 10.2196/jmir.3.2.e20] [Medline: 11720962]

4. Rini C, Porter L, Somers T, McKee D, DeVellis R, Smith M, et al. Automated Internet-based pain coping skills training to manage osteoarthritis pain: a randomized controlled trial. Pain 2015 May;156(5):837-848 [FREE Full text] [doi: 10.1097/j.pain.0000000000000121] [Medline: 25734997]

5. Pua Y, Clark R, Ong P. Evaluation of the Wii Balance Board for walking aids prediction: proof-of-concept study in total knee arthroplasty. PLoS One 2015;10(1):e0117124 [FREE Full text] [doi: 10.1371/journal.pone.0117124] [Medline: 25615952]

6. Hambly K, Griva K. IKDC or KOOS: which one captures symptoms and disabilities most important to patients who have undergone initial anterior cruciate ligament reconstruction? Am J Sports Med 2010 Jul;38(7):1395-1404. [doi: 10.1177/0363546509359678] [Medline: 20351201]

7. Stacey D, Légaré F, Col N, Bennett C, Barry M, Eden K, et al. Decision aids for people facing health treatment or screening decisions. Cochrane Database Syst Rev 2014 Jan 28(1):CD001431. [doi: 10.1002/14651858.CD001431.pub4] [Medline: 24470076]

8. Bright P, Hambly K. What is the proportion of studies reporting patient and practitioner satisfaction with software support tools used in the management of knee pain and is this related to sample size, effect size, and journal impact factor? Telemed J E Health 2017 Dec 21. [doi: 10.1089/tmj.2017.0207] [Medline: 29265954]

9. Vedder A, Cuijpers C, Vantsiouri P, Ferrari M. The Law as a 'Catalyst and Facilitator' for Trust in E-Health: Challenges and Opportunities. Law Innov Technol 2015 May 07;6(2):305-325. [doi: 10.5235/17579961.6.2.305]

10. Darkins A, Kendall S, Edmonson E, Young M, Stressel P. Reduced cost and mortality using home telehealth to promote self-management of complex chronic conditions: a retrospective matched cohort study of 4,999 veteran patients. Telemed J E Health 2015 Jan;21(1):70-76. [doi: 10.1089/tmj.2014.0067] [Medline: 24841071]

11. de la Torre-Díez I, López-Coronado M, Vaca C, Aguado J, de Castro C. Cost-utility and cost-effectiveness studies of telemedicine, electronic, and mobile health systems in the literature: a systematic review. Telemed J E Health 2015 Feb;21(2):81-85 [FREE Full text] [doi: 10.1089/tmj.2014.0053] [Medline: 25474190]

12. Noor N, Razak T, Halim I, Hashim M, Azim A. Technical considerations on the use of Web 2.0 application as telemedicine software tool. In: Proceedings of the 2014 International Conference on Computer Assisted System in Health. Piscataway: IEEE; 2014 Dec Presented at: 2014 International Conference on Computer Assisted System in Health (CASH); Dec 19-21, 2014; Putrajaya, Malaysia p. 73-76 URL: https://www.researchgate.net/publication/ 271475454 Technical Considerations on the Use of Web 20 Application as Telemedicine Software Tool [doi: 10.1109/CASH.2014.12]

13. Patel V, Hale TM, Palakodeti S, Kvedar JC, Jethwani K. Prescription tablets in the digital age: a cross-sectional study exploring patient and physician attitudes toward the use of tablets for clinic-based personalized health care information exchange. JMIR Res Protoc 2015 Oct 19;4(4):e116 [FREE Full text] [doi: 10.2196/resprot.3806] [Medline: 26481906]

14. Woollen J, Prey J, Wilcox L, Sackeim A, Restaino S, Raza ST, et al. Patient experiences using an inpatient personal health record. Appl Clin Inform 2016;7(2):446-460 [FREE Full text] [doi: 10.4338/ACI-2015-10-RA-0130] [Medline: 27437053]

15. Chou W, Prestin A, Lyons C, Wen K. Web 2.0 for health promotion: reviewing the current evidence. Am J Public Health 2013 Jan;103(1):9-18. [doi: 10.2105/AJPH.2012.301071] [Medline: 23153164]

16. Li C, Bernhoff J. Groundswell: Winning in a World Transformed by Social Technologies. Boston: Harvard Business Review Press; 2010.

17. Algeo N, Adams J, Cahill A, Dickson C, Hunter D. A patient and public involvement group study on the usability of the MYJOINTPAIN.ORG website. Rheumatology 2015 Apr 20:141. [doi: 10.1093/rheumatology/kev089.028]

18. Conole G, Alevizou P, Hall W, Keynes M. A Literature Review of the Use of Web 2.0 Tools in Higher Education. 2010. URL: https://www.heacademy.ac.uk/system/files/conole alevizou 2010.pdf [accessed 2018-03-30] [WebCite Cache ID 6yIfaVJg4]

19. Burke P. The Right to Higher Education: Beyond Widening Participation (Foundations and Futures of Education). New York: Routledge; 2012:240.

20. Brown S. From VLEs to learning webs: the implications of Web 2.0 for learning and teaching. Interact Learn Environ 2010 Mar;18(1):1-10. [doi: 10.1080/10494820802158983]

21. Bennett S, Bishop A, Dalgarno B, Waycott J, Kennedy G. Implementing Web 2.0 technologies in higher education: A collective case study. Comput Educ 2012 Sep;59(2):524-534. [doi: 10.1016/j.compedu.2011.12.022]

22. Stellefson M, Chaney B, Barry A, Chavarria E, Tennant B, Walsh-Childers K, et al. Web 2.0 chronic disease self-management for older adults: a systematic review. J Med Internet Res 2013 Feb 14;15(2):e35 [FREE Full text] [doi: 10.2196/jmir.2439] [Medline: 23410671]

23. Huang W, Hood D, Yoo S. Gender divide and acceptance of collaborative Web 2.0 applications for learning in higher education. Internet High Educ 2013 Jan;16:57-65. [doi: 10.1016/j.iheduc.2012.02.001]

24. Williams G, Hamm M, Shulhan J, Vandermeer B, Hartling L. Social media interventions for diet and exercise behaviours: a systematic review and meta-analysis of randomised controlled trials. BMJ Open 2014 Feb 12;4(2):e003926 [FREE Full text] [doi: 10.1136/bmjopen-2013-003926] [Medline: 24525388] 
25. Fuchs B. The writing is on the wall: using Padlet for whole-class engagement. LOEX Quart 2014;40(4):7-9 [FREE Full text]

26. Padlet. 2017. Features URL: https://padlet.com/features [accessed 2017-07-30] [WebCite Cache ID 6sLMG8CEw]

27. van der Eijk M, Faber M, Aarts J, Kremer J, Munneke M, Bloem B. Using online health communities to deliver patient-centered care to people with chronic conditions. J Med Internet Res 2013 Jun 25;15(6):e115 [FREE Full text] [doi: 10.2196/jmir.2476] [Medline: 23803284]

28. Bright P, Hambly K, Tamakloe S. What is the profile of individuals joining the KNEEguru online health community? A cross-sectional mixed-methods study. J Med Internet Res 2016 Apr 18;18(4):e84 [FREE Full text] [doi: 10.2196/jmir.5374] [Medline: 27089531]

29. Giggins O, Persson U, Caulfield B. Biofeedback in rehabilitation. J Neuroeng Rehabil 2013 Jun 18;10:60 [FREE Full text] [doi: 10.1186/1743-0003-10-60] [Medline: 23777436]

30. Distefano L, Blackburn J, Marshall S, Padua D. Gluteal muscle activation during common therapeutic exercises. J Orthop Sports Phys Ther 2009 Jul;39(7):532-540. [doi: 10.2519/jospt.2009.2796] [Medline: 19574661]

31. Gast D, Ledford J. Single Case Research Methodology: Applications in Special Education and Behavioral Sciences. New York: Routledge; 2018.

32. Romeiser-Logan L, Slaughter R, Hickman R. Single-subject research designs in pediatric rehabilitation: a valuable step towards knowledge translation. Dev Med Child Neurol 2017 Dec;59(6):574-580. [doi: 10.1111/dmcn.13405] [Medline: $\underline{\text { 28224606] }}$

33. Box G, Jenkins G, Reinsel G, Ljung G. Time Series Analysis: Forecasting and Control. New Jersey: John Wiley \& Sons; 2015.

34. Ritchie J, Lewis J, Nicholls C, Ormston R. Qualitative Research Practice: A Guide for Social Science Students and Researchers. London: Sage; 2013.

35. Maher C, Lewis L, Ferrar K, Marshall S, De Bourdeaudhuij BI, Vandelanotte C. Are health behavior change interventions that use online social networks effective? A systematic review. J Med Internet Res 2014 Feb 14;16(2):e40 [FREE Full text] [doi: 10.2196/jmir.2952] [Medline: 24550083]

36. Eysenbach G. The law of attrition. J Med Internet Res 2005 Mar 31;7(1):e11 [FREE Full text] [doi: 10.2196/jmir.7.1.e11] [Medline: 15829473]

37. Hassett L, van den Berg M, Lindley R, Crotty M, McCluskey A, van der Ploeg H, et al. Effect of affordable technology on physical activity levels and mobility outcomes in rehabilitation: a protocol for the Activity and MObility UsiNg Technology (AMOUNT) rehabilitation trial. BMJ Open 2016 Dec 06;6(6):e012074 [FREE Full text] [doi: 10.1136/bmjopen-2016-012074] [Medline: 27266776]

38. Pisters M, Veenhof C, Schellevis F, Twisk J, Dekker J, De Bakker D. Exercise adherence improving long-term patient outcome in patients with osteoarthritis of the hip and/or knee. Arthritis Care Res (Hoboken) 2010 Aug;62(8):1087-1094 [FREE Full text] [doi: 10.1002/acr.20182] [Medline: 20235201]

39. Tohyama H, Chiba T, Tadano K, Ikoma K, Yasuda K. Effectiveness of video-based home exercise for osteoarthritis of the knee: a randomized controlled trial. Osteoarthr Cartilage 2010 Oct;18:S26-S27. [doi: 10.1016/S1063-4584(10)60069-6]

40. Kim T, Gay N, Khemka A, Garino J. Internet-based exercise therapy using algorithms for conservative treatment of anterior knee pain: a pragmatic randomized controlled trial. JMIR Rehabil Assist Technol 2016 Dec 14;3(2):e12 [FREE Full text] [doi: 10.2196/rehab.5148] [Medline: 28582256]

41. Calyam P, Mishra A, Antequera R, Chemodanov D, Berryman A, Zhu K, et al. Synchronous Big Data analytics for personalized and remote physical therapy. Pervasive Mob Comput 2016 Jun;28:3-20. [doi: 10.1016/j.pmcj.2015.09.004]

42. Antheunis M, Tates K, Nieboer T. Patients' and health professionals' use of social media in health care: motives, barriers and expectations. Patient Educ Couns 2013 Sep;92(3):426-431. [doi: 10.1016/j.pec.2013.06.020] [Medline: 23899831]

43. Shrestha N, Alsadoon A, Prasad P, Hourany L, Elchouemi A. Enhanced e-health framework for security and privacy in healthcare system. 2016 Presented at: Sixth International Conference on Digital Information Processing and Communications (ICDIPC); Apr 21-23, 2016; Beirut. [doi: 10.1109/ICDIPC.2016.7470795]

44. Premarathne U, Abuadbba A, Alabdulatif A, Khalil I, Tari Z, Zomaya A, et al. Hybrid cryptographic access control for cloud-based EHR systems. IEEE Cloud Comput 2016 Jul;3(4):58-64. [doi: 10.1109/MCC.2016.76]

45. Gravina R, Ma C, Pace P, Aloi G, Russo W, Li W, et al. Cloud-based Activity-aaService cyber-physical framework for human activity monitoring in mobility. Future Gener Comp Sy 2017 Oct;75:158-171. [doi: 10.1016/j.future.2016.09.006]

46. Korda H, Itani Z. Harnessing social media for health promotion and behavior change. Health Promot Pract 2013 Jan;14(1):15-23. [doi: 10.1177/1524839911405850] [Medline: 21558472]

47. Henshaw H, Clark D, Kang S, Ferguson M. Computer skills and internet use in adults aged 50-74 years: influence of hearing difficulties. J Med Internet Res 2012 Aug 24;14(4):e113 [FREE Full text] [doi: 10.2196/jmir.2036] [Medline: 22954484]

48. Konstantinidis E, Billis A, Mouzakidis C, Zilidou V, Antoniou P, Bamidis P. Design, implementation, and wide pilot deployment of FitForAll: an easy to use exergaming platform improving physical fitness and life quality of senior citizens. IEEE J Biomed Health Inform 2016 Jan;20(1):189-200. [doi: 10.1109/JBHI.2014.2378814] [Medline: 26731797] 
49. Wangberg S, Andreassen H, Prokosch H, Santana SV, Sørensen T, Chronaki CE. Relations between Internet use, socio-economic status (SES), social support and subjective health. Health Promot Int 2008 Mar;23(1):70-77. [doi: 10.1093/heapro/dam039] [Medline: 18083686]

50. Ward R, Stevens C, Brentnall P, Briddon J. The attitudes of health care staff to information technology: a comprehensive review of the research literature. Health Info Libr J 2008 Jun;25(2):81-97 [FREE Full text] [doi: 10.1111/j.1471-1842.2008.00777.x] [Medline: 18494643 ]

51. O'Connor S, Hanlon P, O'Donnell CA, Garcia S, Glanville J, Mair FS. Understanding factors affecting patient and public engagement and recruitment to digital health interventions: a systematic review of qualitative studies. BMC Med Inform Decis Mak 2016 Dec 15;16(1):120 [FREE Full text] [doi: 10.1186/s12911-016-0359-3] [Medline: 27630020]

52. Schickedanz A, Huang D, Lopez A, Cheung E, Lyles C, Bodenheimer T, et al. Access, interest, and attitudes toward electronic communication for health care among patients in the medical safety net. J Gen Intern Med 2013 Jul;28(7):914-920 [FREE Full text] [doi: 10.1007/s11606-012-2329-5] [Medline: 23423453]

53. Hemsley-Brown J, Oplatka I. Context and Concepts of Higher Education Consumer Choice. London: Palgrave Macmillan UK; 2016.

54. Melkevik O, Haug E, Rasmussen M, Fismen AS, Wold B, Borraccino A, et al. Are associations between electronic media use and BMI different across levels of physical activity? BMC Public Health 2015 May 19;15:497 [FREE Full text] [doi: 10.1186/s12889-015-1810-6] [Medline: 25986730]

55. Hutchesson M, Morgan P, Callister R, Pranata I, Skinner G, Collins C. Be positive be Healthe: development and implementation of a targeted e-Health weight loss program for young women. Telemed J E Health 2016 Dec;22(6):519-528 [FREE Full text] [doi: 10.1089/tmj.2015.0085] [Medline: 26701611]

56. Gregoski M, Newton J, Ling C, Blaylock K, Smith S, Paguntalan J, et al. Effective weight-loss using an e-health delivered physical activity and dietary intervention: a federal credit union pilot study. Work 2016 Apr 06;54(1):127-134. [doi: 10.3233/WOR-162282] [Medline: 27061690]

57. Bardus M, Blake H, Lloyd S, Suzanne Suggs L. Reasons for participating and not participating in a e-health workplace physical activity intervention. Intl J of Workplace Health Mgt 2014 Nov 04;7(4):229-246. [doi: 10.1108/IJWHM-11-2013-0040]

58. Heinen I, Bullinger M, Kocalevent RD. Perceived stress in first year medical students - associations with personal resources and emotional distress. BMC Med Educ 2017 Jan 06;17(1):4 [FREE Full text] [doi: 10.1186/s12909-016-0841-8] [Medline: 28056972]

59. Quintiliani L, Whiteley J, Johnson E, Viswanath K. Time availability and preference for e-health communication channels for nutrition and physical activity. J Cancer Educ 2013 Sep;28(3):408-411. [doi: 10.1007/s13187-013-0477-x] [Medline: 23653371]

60. Samaha M, Hawi N. Relationships among smartphone addiction, stress, academic performance, and satisfaction with life. Comput Hum Behav 2016 Apr;57:321-325. [doi: 10.1016/j.chb.2015.12.045]

61. Skinner H. Advancing personal health and health care by e-Health technology and health coaching. Int J Non-Commun Dis 2016;1(3):134. [doi: 10.4103/2468-8827.198587]

62. Shameer K, Badgeley M, Miotto R, Glicksberg B, Morgan J, Dudley JT. Translational bioinformatics in the era of real-time biomedical, health care and wellness data streams. Brief Bioinform 2017 Dec;18(1):105-124 [FREE Full text] [doi: 10.1093/bib/bbv118] [Medline: 26876889]

63. Slater H, Dear B, Merolli M, Li L, Briggs A. Use of eHealth technologies to enable the implementation of musculoskeletal Models of Care: Evidence and practice. Best Pract Res Cl RH 2016 Jun;30(3):483-502. [doi: 10.1016/j.berh.2016.08.006]

64. Piwek L, Ellis D, Andrews S, Joinson A. The rise of consumer health wearables: promises and barriers. PLoS Med 2016 Feb;13(2):e1001953 [FREE Full text] [doi: 10.1371/journal.pmed.1001953] [Medline: 26836780]

65. Shadish W, Hedges LV, Pustejovsky JE. Analysis and meta-analysis of single-case designs with a standardized mean difference statistic: a primer and applications. J Sch Psychol 2014 Apr;52(2):123-147. [doi: 10.1016/j.jsp.2013.11.005] [Medline: 24606972]

66. Vohra S, Shamseer L, Sampson M, Bukutu C, Schmid C, Tate R, CENT Group. CONSORT extension for reporting N-of-1 trials (CENT) 2015 Statement. J Clin Epidemiol 2016 Aug;76:9-17 [FREE Full text] [doi: 10.1016/j.jclinepi.2015.05.004] [Medline: 26272792]

67. Zucker D, Ruthazer R, Schmid C. Individual (N-of-1) trials can be combined to give population comparative treatment effect estimates: methodologic considerations. J Clin Epidemiol 2010 Dec;63(12):1312-1323 [FREE Full text] [doi: 10.1016/j.jclinepi.2010.04.020] [Medline: 20863658]

68. Kratochwill T, Levin J. Meta- and statistical analysis of single-case intervention research data: quantitative gifts and a wish list. J Sch Psychol 2014 Apr;52(2):231-235. [doi: 10.1016/j.jsp.2014.01.003] [Medline: 24606977]

69. Mutlu E, Ozdincler A. Reliability and responsiveness of algometry for measuring pressure pain threshold in patients with knee osteoarthritis. J Phys Ther Sci 2015 Jun;27(6):1961-1965 [FREE Full text] [doi: 10.1589/jpts.27.1961] [Medline: 26180358] 
70. Skou S, Simonsen O, Rasmussen S. Examination of muscle strength and pressure pain thresholds in knee osteoarthritis: test-retest reliability and agreement. J Geriatr Phys Ther 2015;38(3):141-147. [doi: 10.1519/JPT.0000000000000028] [Medline: 25594517]

71. Nyvang J, Hedström M, Gleissman S. It's not just a knee, but a whole life: a qualitative descriptive study on patients' experiences of living with knee osteoarthritis and their expectations for knee arthroplasty. Int J Qual Stud Health Well-being 2016;11:30193 [FREE Full text] [Medline: 27036130]

72. Slater H, Jordan J, Chua J, Schütze R, Wark J, Briggs A. Young people's experiences of persistent musculoskeletal pain, needs, gaps and perceptions about the role of digital technologies to support their co-care: a qualitative study. BMJ Open 2016 Dec 09;6(12):e014007 [FREE Full text] [doi: 10.1136/bmjopen-2016-014007] [Medline: 27940635]

73. DeMonte C, DeMonte W, Thorn B. Future implications of eHealth interventions for chronic pain management in underserved populations. Pain Manag 2015;5(3):207-214. [doi: 10.2217/pmt.15.9] [Medline: 25971644]

\section{Abbreviations \\ BMI: body mass index \\ SPC: statistical process control}

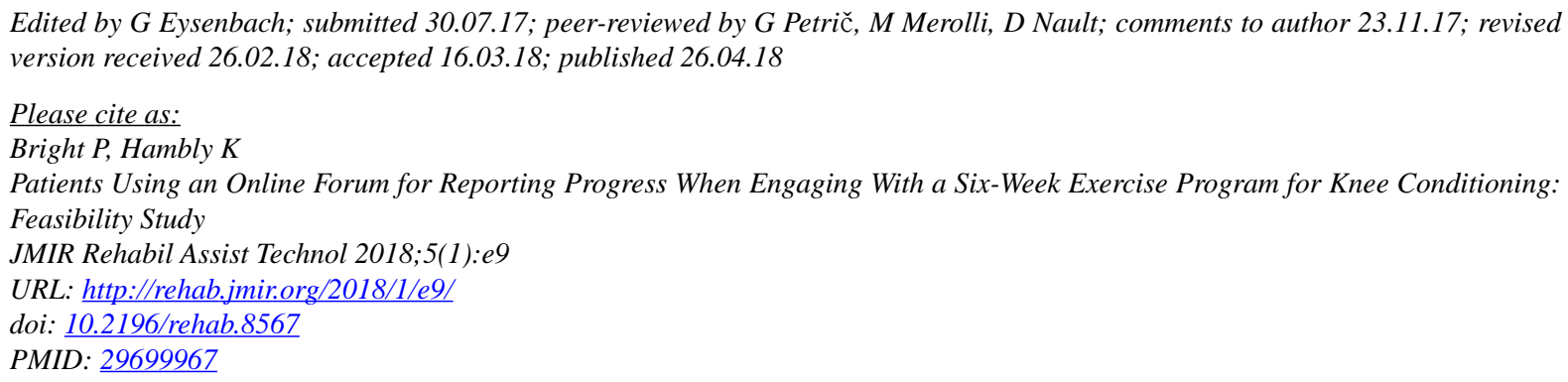

CPhilip Bright, Karen Hambly. Originally published in JMIR Rehabilitation and Assistive Technology (http://rehab.jmir.org), 26.04.2018. This is an open-access article distributed under the terms of the Creative Commons Attribution License (https://creativecommons.org/licenses/by/4.0/), which permits unrestricted use, distribution, and reproduction in any medium, provided the original work, first published in JMIR Rehabilitation and Assistive Technology, is properly cited. The complete bibliographic information, a link to the original publication on http://rehab.jmir.org/, as well as this copyright and license information must be included. 